\title{
Changes in wind activity from 1957 to 2011 and their possible influence on aeolian desertification in northern China
}

\author{
LI Jinchang ${ }^{1,2^{*}}$, LIU Haixia², SU Zhizhu ${ }^{3}$, FAN Xiaohui ${ }^{2}$ \\ ${ }^{1}$ State Key Laboratory of Earth Surface Processes and Resource Ecology, Beijing Normal University, Beijing 100875, China; \\ ${ }^{2}$ Institute of Loess Plateau, Shanxi University, Taiyuan 030006, China; \\ ${ }^{3}$ Historical Culture School, Shanxi University, Taiyuan 030006, China
}

\begin{abstract}
Wind activity is proved to have significant impacts on aeolian desertification. Clarifying the fluctuations and change trend of wind velocity is important for understanding their influence on aeolian desertification. In this study, we used a dataset of wind velocities collected from 93 meteorological stations across northern China from 1957 to 2011 to analyze the changes in wind activity during this period. We tested the monotonic and step (abrupt) trends for annual and seasonal data of mean wind velocity by using Mann-Kendall and Mann-Whitney tests, respectively. The results indicated that the annual mean wind velocity decreased by $0.83 \mathrm{~m} / \mathrm{s}$ from 1957 to 2011 . The decreasing trends were also significant $(P<0.01)$ for each season. The magnitude of the decrease was smallest in the east of northern China and largest in the west of northern China, and the most remarkable decrease occurred in the northwest of northern China. Abrupt decreases in annual and seasonal mean wind velocities occurred in the mid-1980s, which was consistent with the changes in aeolian desertification since the mid-1980s in northern China. As revealed by our study, although both modern aeolian desertification and ecosystem rehabilitation are affected by human activities to some extent, they are also likely to be strongly controlled by climate change, especially by wind activity.
\end{abstract}

Keywords: wind velocity; monotonic trend; step trend; aeolian desertification; northern China

Citation: LI Jinchang, LIU Haixia, SU Zhizhu, FAN Xiaohui. 2015. Changes in wind activity from 1957 to 2011 and their possible influence on aeolian desertification in northern China. Journal of Arid Land, 7(6): 755-764. doi: 10.1007/s40333-015-0050-z

Temperature and precipitation changes caused by climate warming are global issues that have attracted much attention from international communities because of their potential impacts on food security, while wind activity is usually neglected in studies of climate changes. Wind activity has been studied in arid, semi-arid and semi-humid areas because it is one of the key dynamic factors that controls the development of aeolian geomorphology (Wang et al., 2010a), the processes of dust transport and deposition (Wang et al., 2006a; Zhang et al., 2012), and the atmospheric circulation patterns (Perlin et al., 2011; Troccoli et al., 2012). These, in turn, influence the variations in precipitation and temperature
(Bothe et al., 2012; Loikith and Broccoli, 2012), and have significant impacts on aeolian desertification $(\mathrm{Hu}$ et al., 2012; Xie et al., 2012; D'odorico et al., 2013; Dong et al., 2014). Aeolian desertification, as a result of climate change and unsustainable human activity, can be defined as a land degradation process that occurs usually in arid and semi-arid climate zones, and occasionally in semi-humid climate zones (Wang et al., 2012). The form of aeolian desertification poses a threat to the sustainability of human habitat in drylands (Helldén and Tottrup, 2008).

In China, aeolian desertification usually occurs at north of $35^{\circ} \mathrm{N}$, with an annual precipitation $<450 \mathrm{~mm}$

\footnotetext{
*Corresponding author: LI Jinchang (E-mail: lijch@1zb.ac.cn) Received 2015-01-08; revised 2015-03-11; accepted 2015-03-31

(C) Xinjiang Institute of Ecology and Geography, Chinese Academy of Sciences, Science Press and Springer-Verlag Berlin Heidelberg 2015
} 

and a spring precipitation $<90 \mathrm{~mm}$ (Wang et al., 2008a). The main areas with aeolian desertification are usually located in parts of the Tengger and Hobq deserts, most parts of the Gurbantunggut Desert, $\mathrm{Mu}$ Us, Hunshandake, Horqin, Hulun Buir and Nenjiang sandy lands, and regions around the Taklimakan, Badain Jaran and Kumtag deserts (Wang et al., 2008a; Wang et al., 2011) (Fig. 1). Using aerial photos $(1: 50,000)$ in the mid-1970s and mid-1980s, and Landsat TM images in 2000, together with field surveys, Wang et al. $(2003,2004)$ monitored aeolian desertification in northern China and reported that rapid aeolian desertification mainly occurred before the early 1980 s and the recovery of vegetation was significant from the mid-1980s to 2000. At a regional scale, similar change trends of aeolian desertification were reported by Xue et al. (2005) and Yang et al. (2007) for the Otindag Desert, by Wu and Ci (1999, 2002) and Runnström (2003) for the Mu Us Sandy Land, and by Wu (2003) for the Horqin Sandy Land. Fang et al. (2004) also reported that vegetation cover in the desert regions of northern China increased from the mid-1980s to the early 2000s.

Although climate fluctuations and human activities jointly result in aeolian desertification in northern
China, their respective impacts should be evaluated in detail to identify the primary causes (Runnström, 2003; $\mathrm{Xu}$ et al., 2011). To examine the causes of the changes in aeolian desertification, Wang et al. $(2007,2008 \mathrm{~b})$ analyzed the wind activities from 1960 to 1979 and from 1979 to 2003, respectively, by calculating the drift potential (which reflects the wind energy environment and the dust-transport capacity of the wind; Pearce and Walker, 2005), and suggested that the wind activity decreased by $20 \%-50 \%$ after 1979 compared with that in the previous period. However, no research has examined whether the changes of wind activity followed the monotonic trends or revealed steps (abrupt changes) annually and seasonally, especially in spring and winter (which are the main periods that wind erosion occurs because of the low vegetation cover). Clarifying the fluctuations and change trend of wind velocity is important for understanding their influence on aeolian desertification in northern China.

Thus, the objective of this study was to analyze the changes of wind activity (represented by the mean wind velocity) in northern China during the 55-year period from 1957 to 2011. Specially, we aimed to explore the annual and seasonal changes of wind velocities during

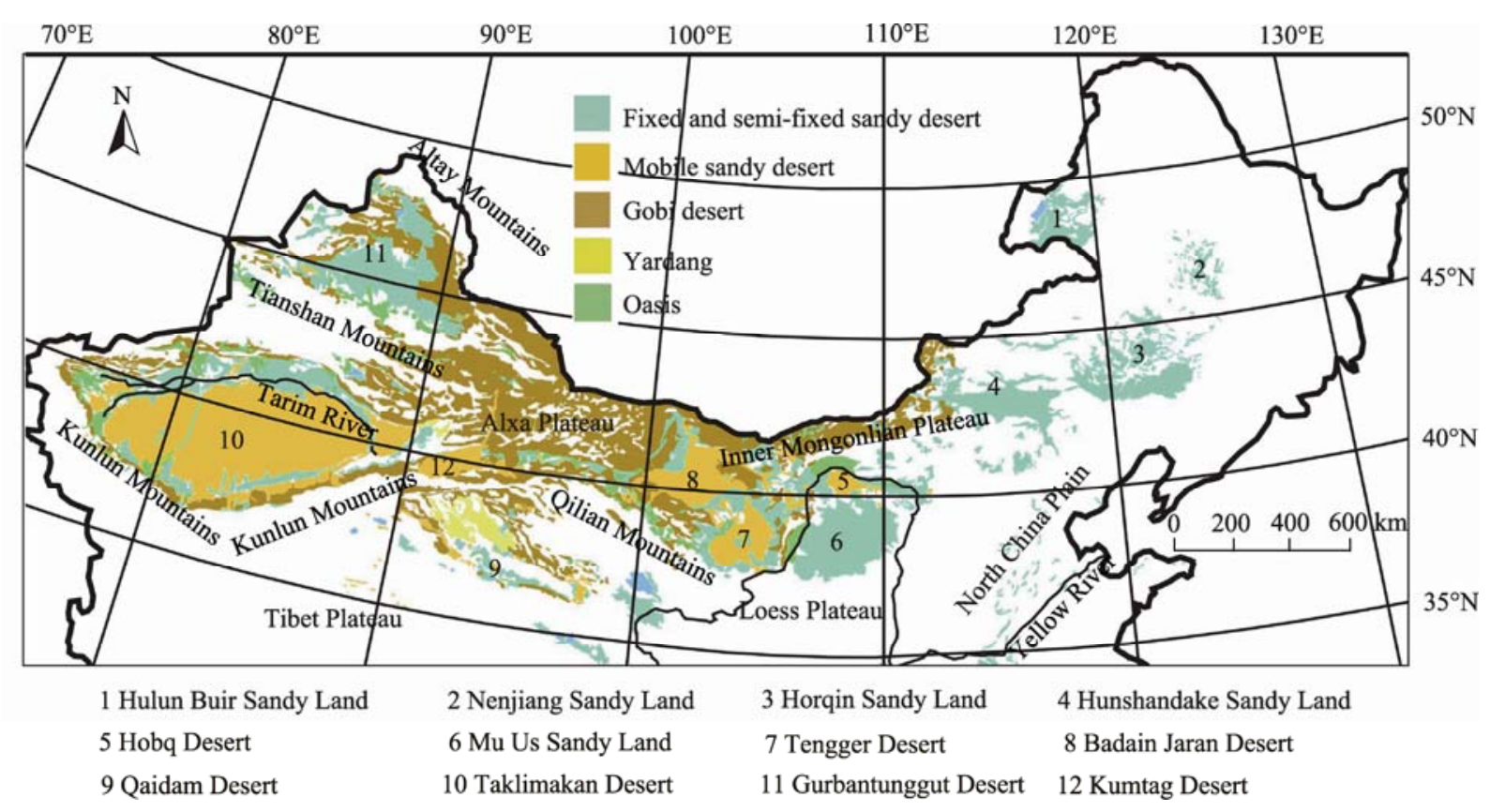

Fig. 1 Distribution of sandy lands and deserts in northern China. This map is based on Wang et al. (2007). 
the study period, and to identify the possible step trends in wind velocity, providing a strong statistical basis for evaluating the influence of wind activity on aeolian desertification in northern China in our future research.

\section{Data and methods}

\subsection{Data sources}

Currently, a total of 115 meteorological stations can provide wind velocity data in northern China. To obtain a reliable estimation of the long-term changes of wind activity, we selected 93 stations that have complete wind velocity records for the 55-year period from 1957 to 2011. Data on the monthly mean wind velocities at these stations were obtained from the China Meteorological Data Sharing System (http:// cdc.cma.gov.cn/home.do). Figure 2 illustrated the locations of the selected meteorological stations. The dataset was subject to stringent error-correction procedures at each of the 93 stations, so the overall quality of the dataset was fairly good.

The monthly mean wind velocities were computed to obtain the seasonal averages for each station based on the following seasonal breakdown: spring (March to May), summer (June to August), autumn (September to November) and winter (December to February next year). The basic monthly mean wind velocity values were also averaged to provide the annual averages. We constructed the averaged seasonal and annual series as the spatial average of the corresponding seasonal and annual series from all the selected stations using an inverse distance-weighted method.

\subsection{Methods}

In hypothesis testing for the long-term changes of wind activity, two types of trends should be considered: monotonic and step (abrupt) trends (Hirsch et al., 1991). Depending primarily on the data distribution, either parametric or nonparametric methods can be used for trend detection. In general, the nonparametric methods perform better relative to the parametric counterparts for non-normal distributions (Hirsch et al., 1991). Because our preliminary analysis showed that several of the time series were non-normal (with a skewness of up to 1.41), we chose the nonparametric Mann-Kendall and Mann-Whitney tests to detect the monotonic and step trends, respectively.

\subsubsection{Mann-Kendall trend test}

We used the MAKESENS Excel template (which provides a Mann-Kendall test for trends and Sen's estimator for the magnitude of the trend) developed by the Finnish Meteorological Institute (Salmi et al., 2002) to detect the monotonic trends. The goal of this test is to verify the null hypothesis $\left(H_{0}\right)$ of no significant trend (in which the observations $x_{i}$ are randomly ordered in time), against the alternative hypothesis $\left(H_{1}\right)$ (in which there is an increasing or decreasing monotonic trend). The Mann-Kendall test statistic (Z) is defined as follows:

$$
Z= \begin{cases}\frac{S-1}{\sqrt{\operatorname{VAR}(S)}} & \text { if } S>0 \\ 0 & \text { if } S=0 \\ \frac{S+1}{\sqrt{\operatorname{VAR}(S)}} & \text { if } S<0\end{cases}
$$

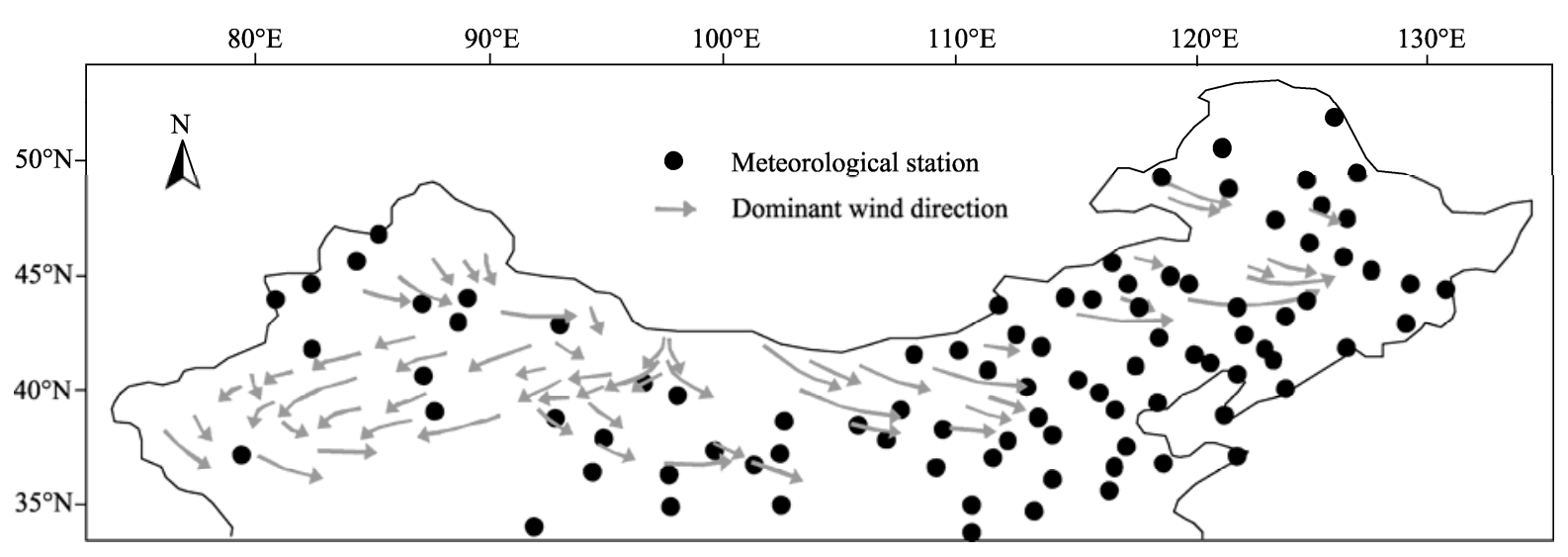

Fig. 2 Locations of the 93 meteorological stations and the dominant surface wind directions in northern China. The dominant surface wind directions are derived from Wang et al. (2004). 


$$
S=\sum_{k=1}^{n-1} \sum_{j=k+1}^{n} \operatorname{sgn}\left(x_{j}-x_{k}\right) .
$$

Where, $x_{j}$ and $x_{k}$ are the values in year $j$ and $k(j>k)$, respectively; $n$ is the length of the dataset (the number of years); and $\operatorname{sgn}\left(x_{j}-x_{k}\right)$ is equal to 1,0 and -1 if $x_{j}-x_{k}$ is greater than, equal to and less than 0 , respectively. In addition, $\operatorname{VAR}(S)$ can be calculated by Eq. 3 .

$$
\operatorname{VAR}(S)=\frac{1}{18}\left[n(n-1)(2 n+5)-\sum_{p=1}^{q} t_{p}\left(t_{p}-1\right)\left(2 t_{p}+5\right)\right] .
$$

Where, $q$ is number of groups with a tie (i.e. with equal values in the two years) and $t_{p}$ is the number of data values in the $p^{\text {th }}$ group.

To test the monotonic trends at the $\alpha$ level of significance, the null hypothesis $H_{0}$ is rejected in favor of the alternative hypothesis $H_{1}$ if the absolute value of $Z$ is greater than $Z_{1-0.5 \alpha}$, where $\pm Z_{1-0.5 \alpha}$ are the $1-0.5 \alpha$ quantiles of the standard normal distribution corresponding to the given significance level $\alpha$ for the test. In MAKESENS, the two-tailed test is used for two different significance levels ( $\alpha=0.05$ or $\alpha=0.01$ ).

To estimate the slope of an existing trend, we used the Sen's nonparametric estimator. Sen's estimator is used in cases where the trend can be assumed to be linear. This means that: $f(t)=Q t+B$, where $Q$ is the slope, $t$ is the year within the study period, and $B$ is a constant (the y-intercept). To estimate the $Q$, we first calculated the slopes between all pairs of data values $j$ and $k(j>k)$ :

$$
Q_{i}=\frac{x_{j}-x_{k}}{j-k} .
$$

We obtained $N=n(n-1) / 2$ slope for estimating $Q_{i}$ if there are $n$ values $x_{j}$ in the time series. Sen's estimator of the slope is the median of these $N$ values of $Q_{i}$. The $N$ values of $Q_{i}$ were ranked from the smallest to the largest, and the Sen's estimator was: $Q=Q_{(N+1) / 2}$ (if $N$ is odd) or $Q=\left(Q_{N / 2}+Q_{(N+2) / 2}\right) / 2$ (if $N$ is even).

To obtain an estimate of $B$, we calculated the $n$ values of the differences $x_{t}-Q_{t}$, where $x_{t}$ is the value in year $t$, and $Q_{t}$ is the slope in year $t$. The median of these values gives an estimate of $B$. The detailed description for the calculations of the Mann-Kendall test statistic $Z$, Sen's slope estimator $Q$, and the constant $B$ can be found in Salmi et al. (2002).

\subsubsection{Step trend test}

A step trend in climatic variables describes an abrupt and persistent change during the recording period from one average value to another (Zhao et al., 2008). We used the Excel template MWST (Mann-Whitney step trend test) to calculate the Mann-Whitney test statistic $T$ based on the procedure described by Conover (1999).

Given data from two random samples, we assigned $X_{1}, X_{2}, \ldots, X_{n}$ denoting a random sample of size $n$ from population 1 and $Y_{1}, Y_{2}, \ldots, Y_{m}$ denoting a random sample of size $m$ from population 2, and ordered the ranks 1 to $N(N=n+m)$ to the observations from the smallest to the largest. Let $R\left(X_{i}\right)$ and $R\left(Y_{i}\right)$ denote the rank assigned to $X_{i}$ and $Y_{i}$ for all $i$ and $j$. The Mann-Whitney test statistic is given as follows:

$$
\begin{gathered}
T=\frac{T_{1}-n \frac{N+1}{2}}{\sqrt{\frac{n m}{N(N-1)}} \sum_{i=1}^{N} R_{i}^{2}-\frac{n m(N+1)^{2}}{4(N-1)}}, \\
T_{1}=\sum_{i=1}^{n} R\left(X_{i}\right) .
\end{gathered}
$$

Where, $\sum R_{i}^{2}$ refers to the sum of the squares of all $N$ of the ranks or average ranks actually used in both samples.

In the Mann-Whitney test, the hypotheses of a two-tailed test can be stated as follows:

$$
\begin{aligned}
& H_{0}: \quad F(x)=G(x), \\
& H_{1}: F(x) \neq G(x) .
\end{aligned}
$$

Where, $F(x)$ and $G(x)$ are the distribution functions corresponding to the samples $X$ and $Y$, respectively. The null hypothesis $H_{0}$ is rejected in favor of the alternative hypothesis $H_{1}$ if the absolute value of $T$ is greater than $T_{1-0.5 \alpha}$, where $\pm T_{1-0.5 \alpha}$ are the $1-0.5 \alpha$ quantiles of the standard normal distribution corresponding to the given significance level $\alpha$ for the test.

\section{Results}

\subsection{Wind velocity characteristics}

Wind velocity across northern China was not significantly correlated with latitude (Pearson's $r=0.112$, $P>0.05)$ or longitude $(r=0.121, P>0.05)$, indicating a lack of obvious zonal distribution of wind velocity at the spatial scale. For example, Chengshantou 
$\left(37^{\circ} 24^{\prime} \mathrm{N}, 122^{\circ} 41^{\prime} \mathrm{E}\right)$ and Linjiang $\left(41^{\circ} 48^{\prime} \mathrm{N}, 126^{\circ} 55^{\prime} \mathrm{E}\right)$ are both located in the east of northern China, but they have the highest $(6.21 \mathrm{~m} / \mathrm{s})$ and lowest $(1.22 \mathrm{~m} / \mathrm{s})$ annual mean wind velocity of northern China, respectively. The regions with higher mean wind velocity were mainly located in the eastern Inner Mongolian Plateau, the Alxa Plateau, the northern Tibet Plateau, the western Gurbantunggut and Tengger deserts, the southern Kumtag Desert, and the Nenjiang and Horqin sandy lands (Figs. 1 and 3), where the mean wind velocity was usually $>3.2 \mathrm{~m} / \mathrm{s}$. However, the regions with lower mean wind velocity were observed in most parts of the Taklimakan Desert and the Loess Plateau (Figs. 1 and 3).

Table 1 summarized the annual and seasonal characteristics of mean wind velocity from 1957 to 2011 . The annual mean wind velocity from 1957 to 2011 in northern China was $2.82 \mathrm{~m} / \mathrm{s}$. The highest and second-highest annual mean wind velocities occurred in $1969(3.31 \mathrm{~m} / \mathrm{s})$ and $1972(3.26 \mathrm{~m} / \mathrm{s})$, respectively; the lowest and second-lowest annual mean wind veloci- ties occurred in $2011(2.38 \mathrm{~m} / \mathrm{s})$ and $2007(2.44 \mathrm{~m} / \mathrm{s})$, respectively. At the seasonal scale, the highest mean wind velocity was observed in winter $(3.18 \mathrm{~m} / \mathrm{s})$, followed by spring $(2.99 \mathrm{~m} / \mathrm{s})$ and autumn $(2.59 \mathrm{~m} / \mathrm{s})$, and then summer $(2.49 \mathrm{~m} / \mathrm{s})$.

\subsection{Monotonic trends in wind velocity}

Figure 4 presented the overall trends of the annual and seasonal mean wind velocities from 1957 to 2011 in northern China. The test results of the monotonic trends in annual and seasonal mean wind velocities are summarized in Table 1.

We found a statistically significant $(P<0.01)$ negative trend in annual mean wind velocity in northern China from 1957 to 2011 both at the annual and seasonal scales. The mean wind velocity decreased at a rate of $0.15 \mathrm{~m} / \mathrm{s}$ per decade (Table 1), for a total decrease of $0.83 \mathrm{~m} / \mathrm{s}(27.1 \%)$ from 1957 to 2011 relative to the average of $3.04 \mathrm{~m} / \mathrm{s}$ in the period from 1957 to 1966. At the seasonal scale, relative to the average from 1957 to 1966 , the largest decrease in mean wind

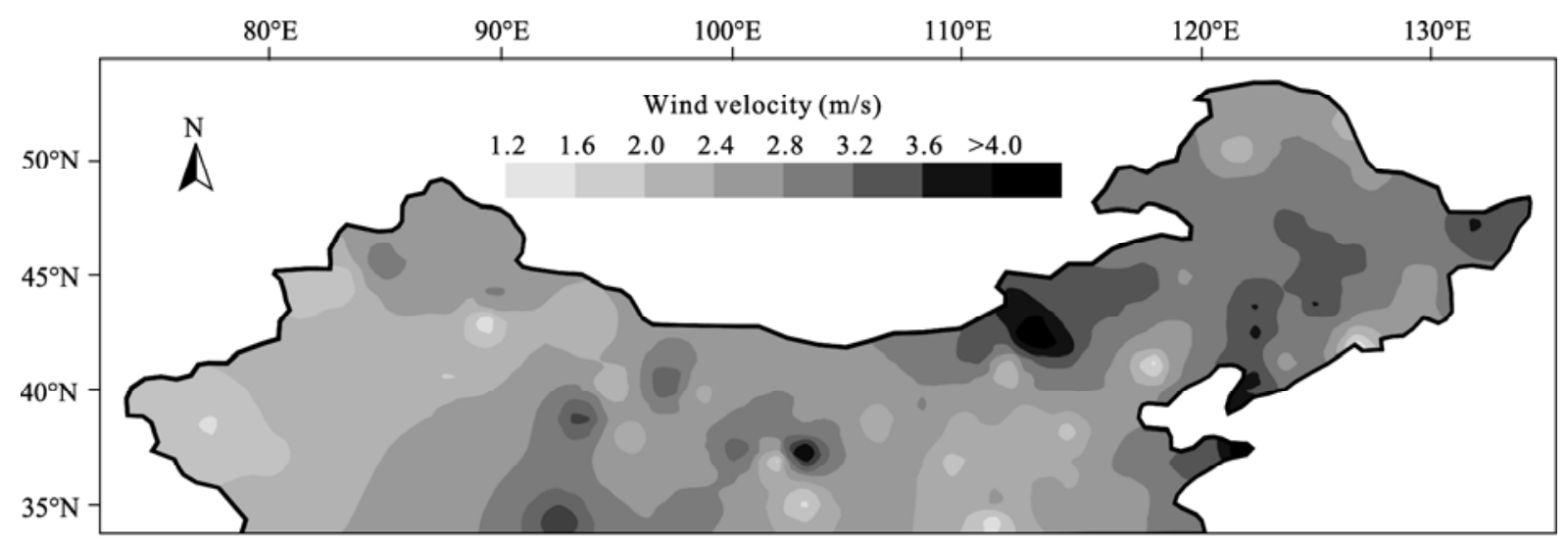

Fig. 3 Distribution of the annual mean wind velocity from 1957 to 2011 in northern China. The isolines are calculated based on the data recorded from 1957 to 2011 at 93 meteorological stations (Fig. 2) using an inverse distance-weighted method.

Table 1 Descriptive statistics of the mean wind velocity from 1957 to 2011 and test results of the significant monotonic trends in northern China

\begin{tabular}{|c|c|c|c|c|c|c|}
\hline \multirow{2}{*}{ Seasonal/Annual } & \multicolumn{3}{|c|}{ Mean wind velocity (m/s) } & \multicolumn{3}{|c|}{ Mann-Kendall test } \\
\hline & Mean & Maximum & Minimum & $Z$ & $Q$ & $B$ \\
\hline Spring & 2.99 & 3.55 & 2.50 & $-4.46^{* *}$ & -0.16 & 3.42 \\
\hline Summer & 2.49 & 3.08 & 2.12 & $-4.25^{* *}$ & -0.11 & 2.81 \\
\hline Autumn & 2.59 & 3.15 & 2.01 & $-6.01^{* *}$ & -0.14 & 3.03 \\
\hline Winter & 3.18 & 3.75 & 2.70 & $-4.94^{* *}$ & -0.17 & 3.64 \\
\hline Annual & 2.82 & 3.31 & 2.38 & $-4.85^{* *}$ & -0.15 & 3.23 \\
\hline
\end{tabular}

Note: ${ }^{* *}$ means significance at $P<0.01$ level. $Z$ is the Mann-Kendall test statistic; $Q$ is the slope of the trend per decade; $B$ is the $y$-intercept. 
velocity occurred in winter $(0.94 \mathrm{~m} / \mathrm{s} ; 27.3 \%)$ and spring $(0.88 \mathrm{~m} / \mathrm{s} ; 27.5 \%)$ while the smallest decrease occurred in autumn $(0.77 \mathrm{~m} / \mathrm{s} ; 26.6 \%)$ and summer $(0.61 \mathrm{~m} / \mathrm{s} ; 23.4 \%)$.

Figure 5 summarized the monotonic trends of annual mean wind velocity from 1957 to 2011 at all the 93 stations. A total of 74 stations showed significant change trends $(P<0.01$ and $P<0.05$ for 64 and 10 stations, respectively), while the remaining 19 stations showed no significant change trend. The most remarkable decrease occurred in the northwest of northern China.

There was a weak but significant negative correlation between the percent decrease of annual mean wind velocity and the longitude for all selected sta-
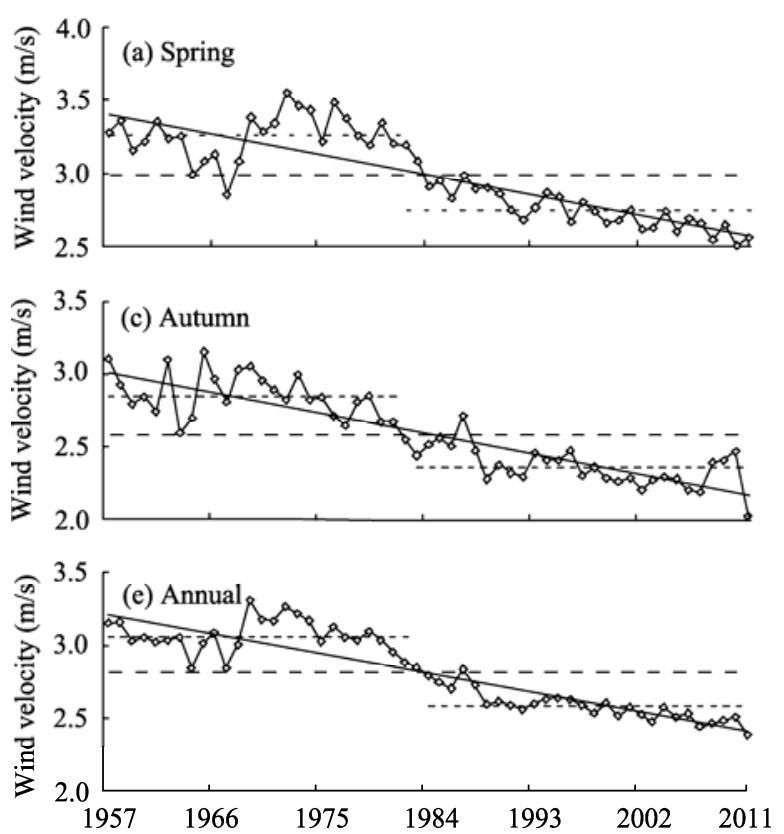

tions ( $r=-0.215, P<0.05$ ), indicating that the magnitude of the decrease increased from east to west in the study region.

\subsection{Step trends in wind velocity}

The seasonal and annual mean wind velocities from 1957 to 2011 can be divided into two periods by step trends: i.e. a period with strong wind activity from 1957 to the early 1980 s, and a period with weak wind activity from the mid-1980s to 2011 (Table 2). Results of the Mann-Whitney test showed a statistically significant difference and abrupt change in annual and seasonal mean wind velocities in the early 1980s, with the mean wind velocity in the second period decreasing by $14.18 \%-17.19 \%$ compared with the value in the
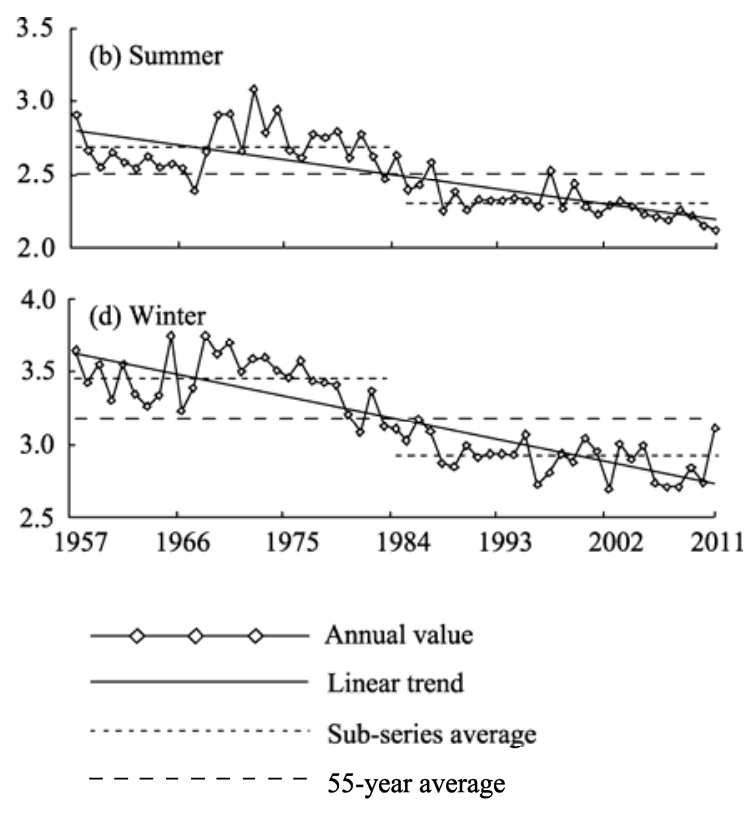

Fig. 4 Changes of the seasonal (a, b, c, d) and annual (e) mean wind velocities from 1957 to 2011 in northern China

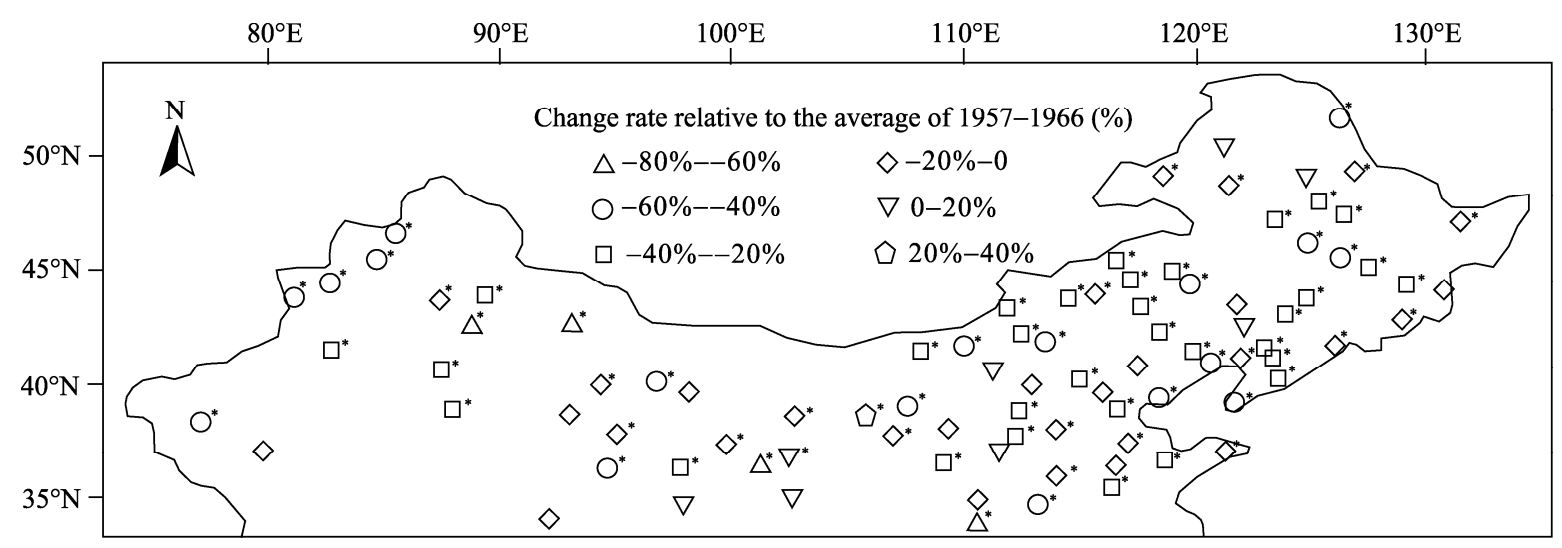

Fig. 5 Monotonic trends in annual mean wind velocity from 1957 to 2011 for all selected stations in northern China. Symbols followed the asterisks indicate statistically significant change at $P<0.05$ level, while symbols without the asterisks indicate no significant change. 
Table 2 Periods separated by step trends and their test results for the seasonal and annual mean wind velocities from 1957 to 2011 in northern China

\begin{tabular}{|c|c|c|c|c|c|c|}
\hline \multirow{2}{*}{ Seasonal/Annual } & \multirow{2}{*}{ Period } & \multirow{2}{*}{ Time series } & \multirow{2}{*}{ Mean wind velocity $(\mathrm{m} / \mathrm{s})$} & \multirow{2}{*}{$\begin{array}{l}\text { Change rate compared with } \\
\text { the first period }(\%)\end{array}$} & \multicolumn{2}{|c|}{ Mann-Whitney test } \\
\hline & & & & & $Z$ & $P$ \\
\hline \multirow{2}{*}{ Spring } & 1 & 1957-1982 & 3.26 & & \multirow{2}{*}{6.01} & \multirow{2}{*}{$<0.01$} \\
\hline & 2 & 1983-2011 & 2.75 & -15.64 & & \\
\hline \multirow{2}{*}{ Summer } & 1 & $1957-1984$ & 2.68 & & \multirow{2}{*}{5.42} & \multirow{2}{*}{$<0.01$} \\
\hline & 2 & $1985-2011$ & 2.30 & -14.18 & & \\
\hline \multirow{2}{*}{ Autumn } & 1 & $1957-1982$ & 2.85 & & \multirow{2}{*}{6.20} & \multirow{2}{*}{$<0.01$} \\
\hline & 2 & $1983-2011$ & 2.36 & -17.19 & & \\
\hline \multirow{2}{*}{ Winter } & 1 & 1957-1983 & 3.45 & & \multirow{2}{*}{6.20} & \multirow{2}{*}{$<0.01$} \\
\hline & 2 & 1984-2011 & 2.92 & -15.36 & & \\
\hline \multirow{2}{*}{ Annual } & 1 & $1957-1983$ & 3.06 & & \multirow{2}{*}{6.31} & \multirow{2}{*}{$<0.01$} \\
\hline & 2 & 1984-2011 & 2.58 & -15.69 & & \\
\hline
\end{tabular}

first period at the seasonal scale. Moreover, the pattern of change trend in seasonal mean wind velocity was similar in each season.

\section{Discussion}

The temporal and spatial changes in mean wind velocity were consistent with those for the drift potential in previous researches (Wang et al., 2006a, 2007), which suggested that the changes in mean wind velocity can indicate the changes in the wind energy environment and the dust-transport capacity of the wind. Wind velocity across northern China was not significantly correlated with the latitude and longitude, indicating that the wind energy environment and dust-transport capacity of the wind are mainly controlled by local topography and the dominant large-scale atmospheric circulation patterns.

The higher mean wind velocity mainly occurred in the eastern Inner Mongolian Plateau, the Alxa Plateau, the northern Tibet Plateau, the western Gurbantunggut and Tengger deserts, the southern Kumtag Desert, and the Nenjiang and Horqin sandy lands, where most of the ground surface is covered by gobi gravels, sandy deserts with vegetated dunes and desert steppes (Wang et al., 2006a). The above-mentioned regions are also the main areas of aeolian desertification in northern China (Wang et al., 2008a). Thus, aeolian desertification appears to be strongly associated with strong local wind activity (Wang et al., 2006b). Regions with lower wind wind velocity were primarily located in the Loess Plateau, where there are extensive areas with loess sediments, and the low wind velocity may be the main cause for the deposit of aeolian dust that originated from the arid northwestern China. The lower mean wind velocity also occurred in most areas of the Taklimakan Desert, which has an extensive area with mobile sandy dunes. The distribution of aeolian geomorphology in this region may be controlled by the combination of the underlying geological deposits, geomorphological setting, soil moisture and vegetation cover (Wang et al., 2007), as well as by the wind activity.

The changes of wind velocity time series in northern China indicated that wind activity was getting weaker from 1957 to 2011. This confirms the decreasing trend of wind activity found by other researchers (Ren et al., 2005; Qian et al., 2007; Yang et al., 2012). Our results showed that the annual mean wind velocity decreased from 1957 to 2011 at a rate of $0.15 \mathrm{~m} / \mathrm{s}$ per decade, which was well above the average for the northern mid-latitudes (about $0.10 \mathrm{~m} / \mathrm{s}$ per decade; Bichet et al., 2012). In the study area, the decreasing rate was greater in northwestern China, which is one of the major sources for dust emission to the Asian and the Pacific regions (Zhang et al., 2003). This suggests that dust transport towards the east may have been decreasing during the study periods. Wind velocity decreased in each season across northern China, with the greater decreases in spring and winter, which were the periods with higher risk of wind-blown sand because of low vegetation cover. This also suggests that there has been a decrease in 
eastward dust transport.

To date, a few studies have linked the variations of wind velocity in eastern tropical Pacific, tropical Atlantic and South America to the changes in sea surface temperature (Bjerknes, 1966; Nobre and Srukla, 1996; Chelton et al., 2001; Song et al., 2009; Rajagopalan and Molnar, 2012). For example, Bjerknes (1966) reported a possible response of atmospheric Hadley circulation to the equatorial ocean temperature anomalies. Song et al. (2009) found a close relationship between sea surface temperature and low-level winds in mesoscale numerical models. The decrease of annual mean wind velocity in northern China may be mostly attributed to the rise of Pacific sea surface temperatures during the past several decades (Rajagopalan and Molnar, 2012). These previous researches suggested that it is important to improve our understanding of the effects of sea surface temperatures on wind velocity in northern China. Clarifying their relationship can provide important advance warning of potentially harmful changes in wind activity.

The trend tests in this study revealed an abrupt change in wind velocity at about the same time in each season. Based on this analysis, we divided the annual and seasonal mean wind velocities from 1957 to 2011 into two periods: a period with strong wind activity from 1957 to the early 1980s and a period with weak wind activity from the mid-1980s to 2011 . Hence, the change trend of aeolian desertification in northern China is consistent with the step trends in wind velocity, but inconsistent with the pattern of continuously increasing human impacts (increases in human and livestock populations and in the area devoted to agriculture) (Wang et al., 2006b, 2008b) and the continuously warming and drying climate in this region since the 1950s (Gao et al., 2008; Liu et al., 2010; Fan and Wang, 2011).

Since 2000, a few key national projects for ecological restoration have been carried out in northern China (e.g. the Natural Forest Protection Project, the Project of Combating Desertification in the Wind/Sand Source Areas Affecting Beijing and Tianjin, and the Returning Farmland to Forest Project), and these may have assisted in the ecological recovery in some regions of northern China. However, these projects were obviously implemented later than the period when rehabilitation began in northern China (i.e. in the mid-1980s). Although the implementation of the Three Norths Forest Shelterbelt Program in northern China was carried out earlier (in 1978), recent research suggested that this program failed to meet its goals because the afforestation covered a relatively low proportion of northern China and did not target the areas with higher risk of aeolian desertification (Wang et al., 2010b). Thus, although human activities undoubtedly had some impacts on aeolian desertification in northern China (Qi et al., 2012; Wang et al., 2012; Yang and $\mathrm{Wu}, 2012$; Wang et al., 2013), our results suggested that climate change, especially changes in wind velocity, may, at least partly, be responsible for decreasing aeolian desertification and increasing rehabilitation of desertified land in northern China. Previous research also indicated that the decrease in wind activity will benefit soil and water conservation, vegetation growth and soil formation by decreasing the land's vulnerability to erosion (Zobeck and Fryrear, 1986).

\section{Conclusions}

In this study, we used a dataset of wind velocity from 1957 to 2011 collected from 93 meteorological stations in northern China to analyze the changes in wind activity during this period. We tested for both monotonic and step (abrupt) trends for annual and seasonal data series in mean wind velocity by using the Mann-Kendall and Mann-Whitney tests, respectively. The results indicated that in northern China, the annual mean wind velocity decreased from 1957 to 2011 at a rate of $0.15 \mathrm{~m} / \mathrm{s}$ per decade, and the decrease rate was greater in northwestern China, which is one of the major sources for dust emission to the Asian and the Pacific regions. The mean wind velocity decreased in each season across northern China, with the greater decreases in spring and winter, which were the periods with higher risk of wind-blown sand because of low vegetation cover.

The trend tests revealed that an abrupt decrease in annual and seasonal mean wind velocities occurred in the mid-1980s. The annual and seasonal mean wind velocities from 1957 to 2011 can be divided into two periods: i.e. a period with strong wind activity from 1957 to the early 1980 s, and a period with weak wind 
activity from the mid-1980s to 2011. Therefore, the change trend of aeolian desertification in northern China was consistent with the step trends in wind velocity. Although both modern aeolian desertification and ecosystem rehabilitation are affected by human activities to some extent, they are also likely to be strongly controlled by climate change, and especially by wind activity.

\section{Acknowledgments}

This research was supported by the Project of the Key Laboratory of Desert and Desertification, Chinese Academy of Sciences (KLDD-2014-001), the Project of the State Key Laboratory of Earth Surface Processes and Resource Ecology, Beijing Normal University (2015-KF-07), the Science \& Technology Pillar Program of Shanxi Province (20121101011) and the Soft Science Program of Shanxi Province (2015041020-1).

\section{References}

Bichet A, Wild M, Folini D, et al. 2012. Causes for decadal variations of wind speed over land: Sensitivity studies with a global climate model. Geophysical Research Letters, 39(11), doi: 10.1029/2012GL051685.

Bjerknes B J. 1966. A possible response of the atmospheric Hadley circulation to equatorial anomalies of ocean temperature. Tellus, 18: $820-829$

Bothe O, Fraedrich K, Zhu X H. 2012. Precipitation climate of Central Asia and the large-scale atmospheric circulation. Theoretical and Applied Climatology, 108: 345-354.

Chelton D B, Esbensen S K, Schlax M G, et al. 2001. Observations of coupling between surface wind stress and sea surface temperature in the eastern tropical Pacific. Journal of Climate, 14: 1479-1498.

Conover W J. 1999. Practical Nonparametric Statistics ( $3^{\text {rd }}$ ed.). New York: John Wiley Press, 36-51.

D'odorico P, Bhattachan A, Davis K F, et al. 2012. Global desertification: drivers and feedbacks. Advances in Water Resources, 51: 326-344.

Dong Z B, Lv P, Zhang Z C, et al. 2014. Aeolian transport over a developing transverse dune. Journal of Arid Land, 6(3): 243-254.

Fan X H, Wang M B. 2011. Change trends of air temperature and precipitation over Shanxi Province, China. Theoretical and Applied Climatology, 103: 519-531.

Fang J T, Piao S L, He J S, et al. 2004. Increasing terrestrial vegetation activity in China, 1982-1999. Science in China: Life Sciences, 47(3): 229-240.

Gao X, Shi Y, Song R, et al. 2008. Reduction of future monsoon precipitation over China: comparison between a high resolution RCM simulation and the driving GCM. Meteorology and Atmospheric Physics, 100(1-4): 73-86.

Helldén U, Tottrup C. 2008. Regional desertification: a global synthesis. Global and Planetary Change, 64(3-4): 169-176.

Hirsch R M, Alexander R B, Smith R A. 1991. Selection of methods for the detection and estimation of trends in water quality. Water Re- sources Research, 27: 803-813.

Hu G Y, Dong Z B, Lu J F, et al. 2012. Driving forces responsible for aeolian desertification in the source region of the Yangtze River from 1975 to 2005. Environmental Earth Sciences, 66: 257-263.

Liu Y, Li X, Zhang Q, et al. 2010. Simulation of regional temperature and precipitation in the past 50 years and the next 30 years over China. Quaternary International, 212(1): 57-63.

Loikith P C, Broccoli A J. 2012. Characteristics of observed atmospheric circulation patterns associated with temperature extremes over North America. Journal of Climate, 25(20): 7266-7281.

Nobre P, Srukla J. 1996. Variations of sea surface temperature, wind stress, and rainfall over the tropical Atlantic and South America. Journal of Climate, 9: 2464-2479.

Pearce K I, Walker I J. 2005. Frequency and magnitude biases in the "Fryberger" model, with implications for characterizing geomorphically effective winds. Geomorphology, 68: 39-55.

Perlin N, Skyllingstad E D, Samelson R M. 2011. Coastal atmospheric circulation around an idealized cape during wind-driven upwelling studied from a Coupled Ocean-Atmosphere Model. Monthly Weather Review, 139(3): 809-829.

Qi Y B, Chang Q R, Jia K L, et al. 2012. Temporal-spatial variability of desertification in an agro-pastoral transitional zone of northern Shaanxi Province, China. Catena, 88(1): 37-45.

Qian W H, Fu J L, Zhang W W, et al. 2007. Changes in mean climate and extreme climate in China during the last 40 years. Advances in Earth Science, 22(7): 673-684. (in Chinese)

Rajagopalan B, Molnar P. 2012. Pacific Ocean sea-surface temperature variability and predictability of rainfall in the early and late parts of the Indian summer monsoon season. Climate Dynamics, 39(6): 1543-1557.

Ren G Y, Guo J, Xu M Z, et al. 2005. Climate changes of mainland China over the past half century. Acta Meteorologica Sinica, 63(6): 942-956. (in Chinese)

Runnström M C. 2003. Rangeland development of the Mu Us sandy land in semiarid China: an analysis using Landsat and NOAA remote sensing data. Land Degradation \& Development, 14: 189-202.

Salmi T, Määttä A, Anttila P, et al. 2002. Detecting trends of annual values of atmospheric pollutants by the Mann-Kendall test and Sen's slope estimates-the Excel template application MAKESENS. Publications on Air Quality 31. Finnish Meteorological Institute, Helsinki, Finland.

Song Q T, Chelton D B, Esbensen S K, et al. 2009. Coupling between sea surface temperature and low-level winds in mesoscale numerical models. Journal of Climate, 22: 146-164.

Troccoli A, Muller K, Coppin P, et al. 2012. Long-term wind speed trends over Australia. Journal of Climate, 25(1): 170-183.

Wang G Q, Wang X Q, Wu B, et al. 2012. Desertification and its mitigation strategy in China. Journal of Resources and Ecology, 3(2): 97-104.

Wang T, Wu W, Xue X, et al. 2003. Time-space evolution of desertification land in northern China. Journal of Desert Research, 23: 230-235. (in Chinese)

Wang T, Wu W, Xue X, et al. 2004. Spatial-temporal changes of sandy desertified land during last 5 decades in northern China. Acta Geo- 
graphica Sinica, 59: 203-212. (in Chinese)

Wang T, Song X, Yan C Z, et al. 2011. Remote sensing analysis on aeolian desertification trends in northern China during 1975-2010. Journal of Desert Research, 31(6): 1351-1356. (in Chinese)

Wang T, Yan C Z, Song X, et al. 2012. Monitoring recent trends in the area of aeolian desertified land using Landsat images in China's Xinjiang region. Journal of Photogrammetry and Remote Sensing, 68: $184-190$.

Wang T, Xue X, Zhou L, et al. 2013. Combating aeolian desertification in northern China. Land Degradation \& Development, 26(2): $118-132$.

Wang X M, Dong Z B, Zhang J W, et al. 2004. Modern dust storms in China: an overview. Journal of Arid Environments, 58: 559-574.

Wang X M, Zhou Z J, Dong Z B. 2006a. Control of dust emissions by geomorphic conditions, wind environments and land use in northern China: An examination based on dust storm frequency from 1960 to 2003. Geomorphology, 81: 292-308.

Wang X M, Chen F H, Dong Z B. 2006b. The relative role of climatic and human factors in desertification in semiarid China. Global Environmental Change, 16: 48-57.

Wang X M, Hasi E, Zhou Z J, et al. 2007. Significance of variations in the wind energy environment over the past 50 years with respect to dune activity and desertification in arid and semiarid northern China. Geomorphology, 86: 252-266.

Wang X M, Chen F H, Hasi E, et al. 2008a. Desertification in China: An assessment. Earth-Science Reviews, 88: 188-206.

Wang X M, Li J J, Dong G R, et al. 2008b. Responses of desertification to variations in wind activity over the past five decades in arid and semiarid areas in China. Chinese Science Bulletin, 53(3): 426-433.

Wang X M, Zhang C X, Zhang J W, et al. 2010a. Nebkha formation: Implications for reconstructing environmental changes over the past several centuries in the Ala Shan Plateau, China. Palaeogeography, Palaeoclimatology, Palaeoecology, 297: 697-706.

Wang X M, Zhang C X, Hasi E, et al. 2010b. Has the Three Norths Forest Shelterbelt Program solved the desertification and dust storm problems in arid and semiarid China? Journal of Arid Environments, 74: 13-22.

Wu B, Ci L J. 1999. Developing stages and causes of desertification in the $\mathrm{Mu}$ Us sandland. Chinese Science Bulletin, 44: 845-849.
Wu B, Ci L J. 2002. Landscape change and desertification development in the Mu Us Sandland, Northern China. Journal of Arid Environments, 50: 429-444.

Wu W. 2003. Dynamic monitor to evolvement of sandy desertified land in Horqin Region for the last 5 decades, China. Journal of Desert Research, 23: 646-651. (in Chinese)

Xie S B, Qu J J, Zu R P, et al. 2012. New discoveries on the effects of desertification on the ground temperature of permafrost and its significance to the Qinghai-Tibet Plateau. Chinese Science Bulletin, 57(8): 838-842.

Xu D Y, Li C L, Zhuang D F, et al. 2011. Assessment of the relative role of climate change and human activities in desertification: A review. Journal of Geographical Science, 21(5): 926-936.

Xue X, Wang T, Wu W. 2005. The desertification development and its causes of agro-pastoral mixed regions in North China. Journal of Desert Research, 25: 520-528. (in Chinese)

Yang L H, Wu J G. 2012. Knowledge-driven institutional change: An empirical study on combating desertification in northern China from 1949 to 2004. Journal of Environmental Management, 110: 254-266.

Yang X, Ding Z, Fan X, et al. 2007. Processes and mechanisms of desertification in northern China during the last 30 years, with a special reference to the Hunshandake Sandy Land, eastern Inner Mongolia. Catena, 71(1): 2-12.

Yang Z C, Li Y L, Cui D, et al. 2012. Changes of main climatic parameters and potential evapotranspiration in typical semi-arid sandy lands of northern China during 1951-2005. Journal of Desert Research, 32(5): 1384-1392. (in Chinese)

Zhang K C, Qu J J, Han Q J, et al. 2012. Wind energy environments and aeolian sand characteristics along the Qinghai-Tibet Railway, China. Sedimentary Geology, 273-274: 91-96.

Zhang X Y, Gong S L, Zhao T L, et al. 2003. Sources of Asian dust and role of climate change versus desertification in Asian dust emission. Geophysical Research Letters, 30(24), 2272, doi: 10.1029/2003GL018206.

Zhao F F, Xu Z X, Huang J X, et al. 2008. Monotonic trend and abrupt changes for major climate variables in the headwater catchment of the Yellow River basin. Hydrological Processes, 22: 4587-4599.

Zobeck T M, Fryrear D W. 1986. Chemical and physical characteristics of windblown sediment II: chemical characteristics and total soil and nutrient discharge. Transactions of the American Society of Agricultural Engineers, 29: 1037-1041. 